\title{
Beginning of percutaneous coronary interventions: Zurich 1976-1977
}

\author{
Marko Turina, MD
}

By introducing his concept of percutaneous coronary intervention (PCI), Andreas Grüntzig (Figure 1) has affected the most profound change not only in cardiology but also in cardiac surgery. This innovation started its triumphal march in the last 2 decades of the 20th century, but the idea was developed and experimentally tested in Zurich in 1974 to 1975. The concept of a balloon-tipped catheter to dilate arteriosclerotic lesions was doubted by many, and early clinical application of PCI was anything but straightforward. Having had the privilege to work closely with Andreas Grüntzig during the development of PCI in Zurich, I was invited by Dr Lawrence Cohn, Editor-in-Chief, to add some observations about this epochal discovery. Two observations emerge from Dr Grüntzig's early work in Zurich: (1) percutaneous balloon dilatation of the coronary stenosis was neither a divine inspiration nor a stroke of luck, but a product of long development and thorough experimental evaluation; (2) its first clinical application was by no means as simple as it appears today.

\section{EXPERIMENTAL DEVELOPMENT OF PCI}

Following pioneering work of Dotter and Judkins ${ }^{1}$ in transluminal dilatation of atherosclerotic lesions in peripheral arteries, Andreas Grüntzig became interested in improving this particular method by replacing staged catheter dilatation with dilatation of the stenosis with a balloon-tipped catheter. After his first success in iliac and femoral arteries, ${ }^{2}$ he realized that such a technique could be applicable to coronary arteries as well. There was widespread skepticism about his ideas among cardiologists and surgeons ("Where would the stenotic material go?" or "You will not be able to dilate calcified lesions!"), and there was also a general belief that the heart would not tolerate any ischemia during inflation of the balloon. Grüntzig was determined to test his method in animals, and he approached me with the request for a suitable experimental model. At that time I was in charge of cardiosurgical research in the University Hospital, and in 1974 to 1975 we embarked on a series of canine experiments to test the applicability of balloon dilatation of coronary stenosis. First, a precisely calibrated, survivable stenosis of the coro-

From University Hospital Haldenbach, Zurich, Switzerland.

Received for publication Dec 17, 2010; revisions received Jan 4, 2011; accepted for publication Jan 24, 2011.

Address for reprints: Marko Turina, MD, Professor of Surgery University Hospital Haldenbach 18 Zurich Switzerland (E-mail: marko.turina@usz.ch).

J Thorac Cardiovasc Surg 2011;141:1342-3

$0022-5223 / \$ 36.00$

Copyright (c) 2011 by The American Association for Thoracic Surgery

doi:10.1016/j.jtcvs.2011.01.045

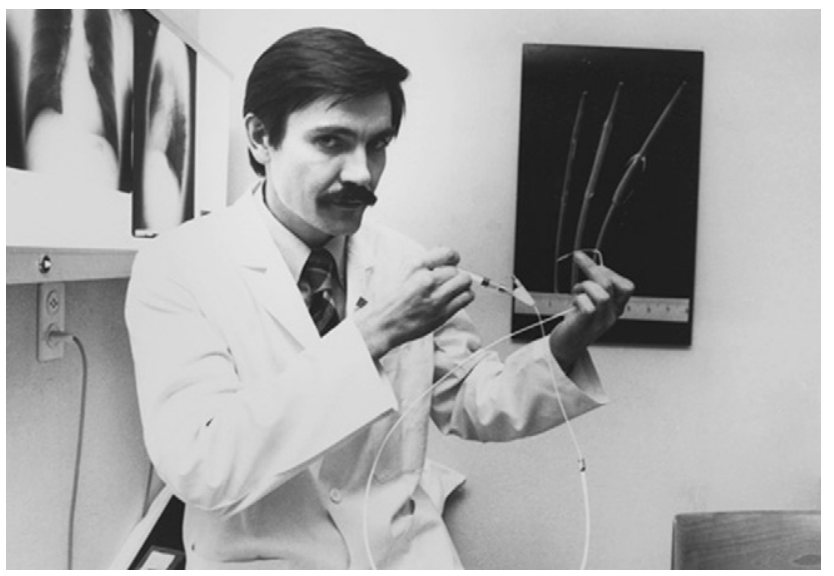

FIGURE 1. Andreas Grüntzig.

nary artery had to be developed; this was done by placing narrowing ligatures around the anterior descending or circumflex coronary artery. A further series of experiments was needed to select the material for creating this stenosis, the constraint being the capacity of Grüntzig's balloon catheter to break the suture. We soon determined that the balloon catheter was able to break a 6-0 silk suture but was unable to break 5-0 silk or any Prolene polypropylene suture (Ethicon, Inc, Somerville, NJ). Furthermore, we found that too narrow a stenosis $(1 \mathrm{~mm})$ in $15-$ to $20-\mathrm{kg}$ animals led to electrical and hemodynamic instability, so we decided to construct a chronic $1.5-\mathrm{mm}$ stenosis by passing a $6-0$ silk ligature around the coronary artery. The heart was approached through a left anterior thoracotomy, either the left anterior descending or circumflex coronary artery was carefully dissected, and the suture was tied over a graduated probe, which guaranteed residual vessel patency and a precisely calibrated stenosis. At that time our experimental cardiosurgical laboratory had excellent angiographic equipment, allowing Grüntzig to perform cardiac catheterization immediately after surgery, without resorting to the catheter suite in the main hospital building. Dilatation trials (breaking the ligature) in dogs with coronary stenosis were first done in short-term experiments, with the chest open. After the validity of chronic coronary stenosis and the concept of a balloon-tipped catheter had been established, a series of long-term experiments was performed, in which the animals were allowed to recover for several weeks after placement of the coronary stenosis before being subjected to balloon dilatation.

An important element in the early development of PCI was the belief that some distal perfusion is necessary to assure myocardial viability during balloon inflation, considered to be necessary for 10 to 20 seconds. The original 


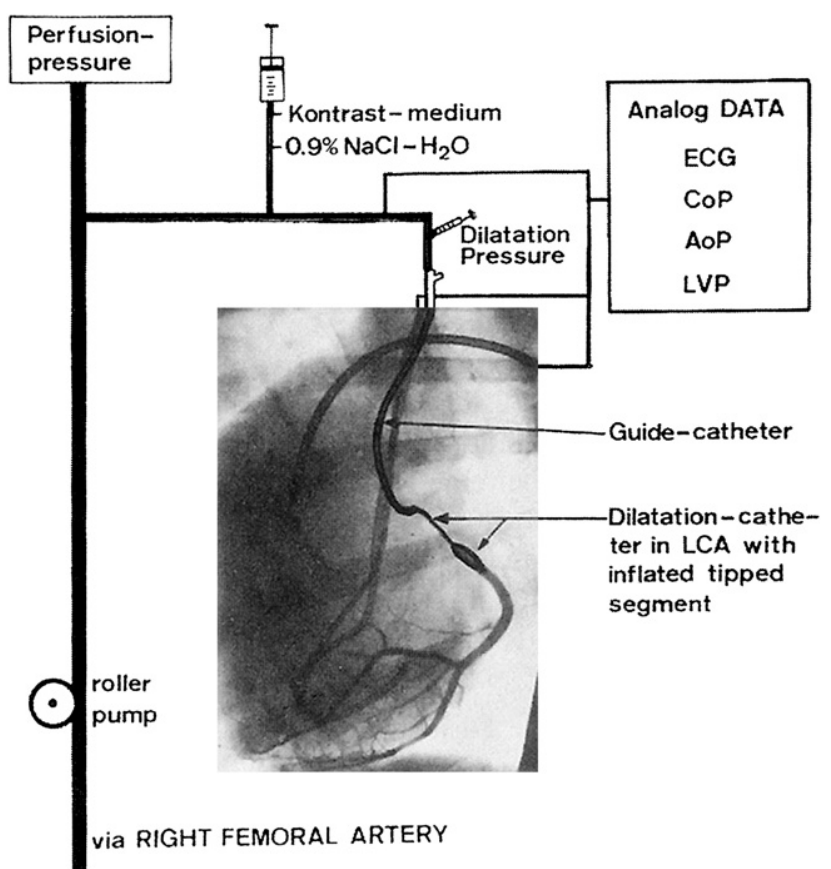

FIGURE 2. The original setup consisted of a roller pump interposed between a large-bore catheter in the femoral artery and the tip of a coronary dilatation catheter, allowing a perfusion rate of 50 to $100 \mathrm{~mL} / \mathrm{min}$ delivered to the distal coronary bed during placement and inflation of the balloon. The second catheter lumen was connected to the balloon itself, with pressure being applied manually. ECG, Electrocardiogram; CoP, coronary pressure; $A o P$, aortic pressure; $L V P$, left ventricular pressure; $L C A$, left coronary artery. (From Grüntzig A. Perkutane Dilatation von Coronarstenosen-Beschreibung eines neuen Kathetersystems. Klin Wochenschr. 1976;54:543-5. Published with permission of SpringerVerlag Wien.)

setup (Figure 2) consisted of a roller pump interposed between large-bore catheters in the femoral artery and the tip of the coronary dilatation catheter, allowing a perfusion rate of 50 to $100 \mathrm{~mL} / \mathrm{min}$ delivered to the distal coronary bed during placement and inflation of the balloon. The second catheter lumen was connected to the balloon itself, with pressure being applied manually. The method was described in 2 scientific articles published in German ${ }^{3,4}$ but did not elicit much interest. We tried to publish the results in English, but even the American Society for Artificial Internal Organs, usually inclined to accept courageous and innovative communications, in 1976 did not consider our work important enough for oral presentation. It was only published as abstract and did not enter the Medline registry.

Distal perfusion with oxygenated blood was later found to be unnecessary, greatly simplifying the manipulation of balloon catheter. This change enabled the first successful clinical PCI applications. Grüntzig's ${ }^{5}$ original letter to the Editor in Lancet in 1978 described successful clinical application in 5 patients, and this is how PCI was introduced to the world of cardiology.

\section{FIRST CLINICAL APPLICATIONS}

Initially there was widespread skepticism in cardiology and internal medicine toward Grüntzig's method, best reflected by the fact that Andreas Grüntzig had to wait in Zurich for more than 2 months after his first successful coronary dilatation to have a second patient referred for this procedure. After mentioning his initial success to colleagues, he was invited by Professor Kaltenbach, at that time head of cardiology at the University Hospital in Frankfurt, to perform his procedure there, and indeed 2 of his first 5 successful PCIs were performed not in Zurich, but in Frankfurt. It is also interesting to note that it took Grüntzig 3 months to perform his first 5 coronary interventions owing to lack of enthusiasm for this procedure among referring physicians.

\section{RISKS OF EARLY PCI}

The first surgical aspects of the procedure were summarized in our publication from $1979 .{ }^{6}$ In brief, the method was attempted in 45 patients, but the coronary stenosis could not be passed with the catheter in 12. Among the 33 remaining patients in whom the stenosis could be passed with the dilatation catheter, PCI was successful in 28, yielding an overall success rate of $62 \%$. Emergency coronary bypass had to be performed in $4(9 \%)$ patients, in some of them with continuing resuscitation before placement of the bypass graft. In some of these patients there was even no time to prepare the pump-oxygenator, and I had to perform saphenous vein anastomosis on the beating heart, of course without the benefit of a stabilizer or blower. After these narrow escapes, a surgical operating room was kept available at full alert when PCI was being performed, to minimize risks to the patient.

This historical vignette demonstrates that PCI, this monumental breakthrough in the treatment of coronary artery disease, succeeded because of thorough experimental preparation; its clinical application became possible only with solid cardiosurgical support, necessary to prevent deleterious outcomes in not so rare, abrupt closure of the dilated coronary artery in the early stages of PCI development.

\section{References}

1. Dotter CT, Judkins MP. Transluminal treatment of arteriosclerotic obstruction. Description of a new technique and a preliminary report of its application. Circulation. 1964;30:654-70.

2. Grüntzig A, Hopff H. Percutaneous recanalization after chronic arterial occlusion with a new dilator-catheter (modification of the Dotter technique. Dtsch Med Wochenschr. 1974;99:2502-5.

3. Grüntzig A. Perkutane Dilatation von Coronarstenosen-Beschreibung eines neuen Kathetersystems. Klin Wochenschr. 1976;54:543-5.

4. Grüntzig A, Riedhammer HH, Turina M, Rutishauser W. Eine neue Methode zur perkutanen Dilatation von Koronarstenosen-tierexperimentelle Prüfung. Verh Dtsch Ges Kreislaufforsch. 1976;42:282-5.

5. Gruntzig A. Transluminal dilatation of coronary-artery stenosis. Lancet. 1978; 1(8058):263.

6. Turina M, Gruntzig A, Krayenbuhl C, Senning A. The role of the surgeon in percutaneous transluminal dilation of coronary stenosis. Ann Thorac Surg. 1979;28: 103-12. 